\title{
Aortic pseudocoarctation: a very rare finding
}

\author{
Filipa Cordeiro, Sofia Silva Carvalho, Alberto Ferreira, Jose Ilidio Moreira
}

Cardiology Department, Centro Hospitalar de Tras-os-Montes e Alto Douro, Vila Real, Portugal

\section{Correspondence to}

Dr Filipa Cordeiro,

filipabritocordeiro@gmail.com

Accepted 28 February 2018

\section{DESCRIPTION}

A 52-year-old Caucasian woman with a history of hypertension since age 30 was referred to cardiology department due to aortic stenosis. She had exertional dyspnoea, without thoracic pain or syncope. There was no blood pressure gradient between upper and lower extremities. Transthoracic echocardiography revealed bicuspid aortic valve, severe valvular aortic stenosis and dilation of ascending aorta (figure 1). There was also a tapering

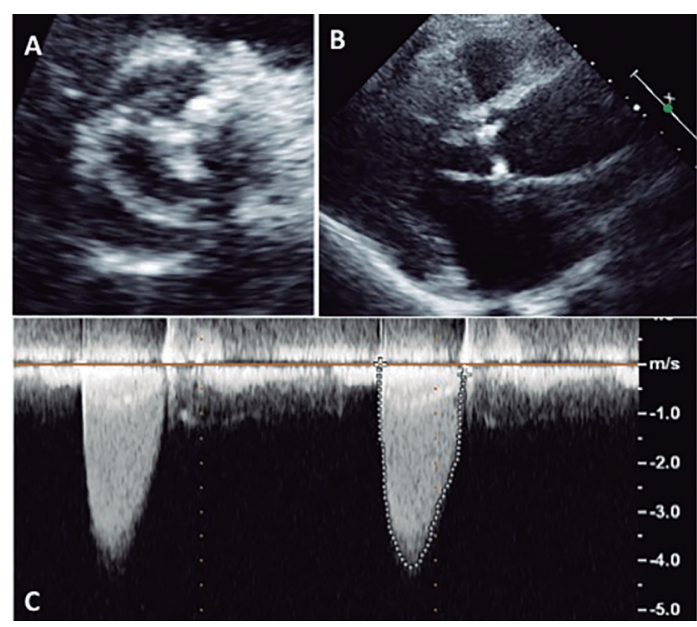

Figure 1 Transthoracic echocardiography. (A) Bicuspid aortic valve with fusion of the right and left cusps and superimposed calcific changes. (B) Dilatation of the ascending aorta. (C) Continuous wave Doppler of aortic stenosis jet revealing a peak velocity above $4 \mathrm{~m} / \mathrm{s}$, consistent with severe stenosis.

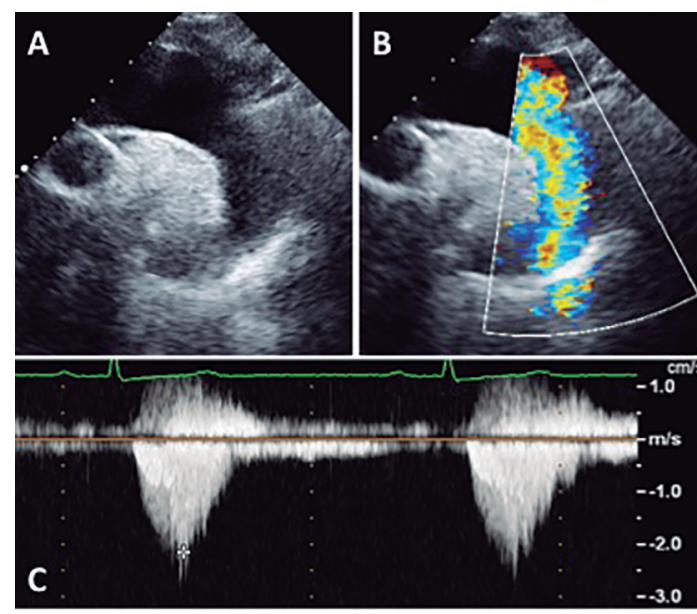

Figure 2 Suprasternal view of transthoracic echocardiography. (A) Tapering of the descending aorta. (B) Colour Doppler demonstrating acceleration and turbulent flow within the descending aorta. (C) Continuous wave Doppler revealing a peak systolic gradient of $19 \mathrm{~mm} \mathrm{Hg}$, without diastolic run-off.
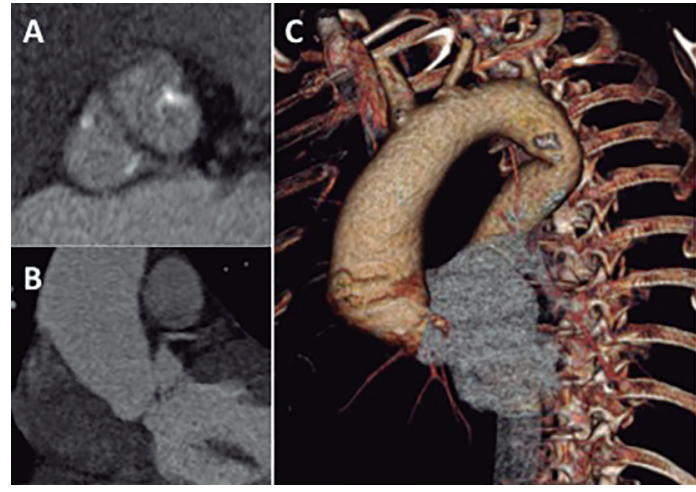

Figure 3 CT angiography. (A) Bicuspid aortic valve. (B) Dilatation of the ascending aorta. (C) Elongation of the distal aortic arch and focal kinking at the aortic isthmus, without significant stenosis or enlarged collateral arteries.

of the descending aorta, with turbulent flow and a systolic peak gradient of $19 \mathrm{~mm} \mathrm{Hg}$ (figure 2). To assess the thoracic aorta, the patient underwent CT angiography, which revealed elongation of the distal aortic arch, a focal kinking at the aortic isthmus, and absence of significant stenosis and enlarged collateral arteries, consistent with aortic pseudocoarctation (figure 3).

Aortic pseudocoarctation is a very rare congenital anomaly of the aortic arch and can coexist with other congenital heart diseases, such as bicuspid aortic valve. ${ }^{1}$ It mimics true coarctation, but can be differentiated from it by recognising a high, elongated arch, a kinking that lacks luminal narrowing and an absence of enlarged collateral arteries. ${ }^{2}$ The identification of aortic pseudocoarctation can be an incidental finding or associated with hypertension and symptoms related to compression of adjacent structures. ${ }^{1}$ Its management is not well established, but surgical

\section{Learning points}

Aortic pseudocoarctation is a very rare congenital anomaly that mimics coarctation, but lacks significant luminal narrowing and enlarged collateral arteries.

- Although less severe than true coarctation, it should not be regarded as a benign condition. Surgical treatment has been proposed in symptomatic patients or when associated with aortic aneurysms, and regular follow-up in asymptomatic patients without associated anomalies.

- This case highlights the importance of echocardiographic suprasternal view to identify aortic coarctation or pseudocoarctation as a cause of secondary hypertension. 
treatment has been proposed in symptomatic patients or when associated with aortic aneurysms. ${ }^{3}$ The case was discussed in a multidisciplinary team, and it was decided that the pseudocoarctation did not require intervention and should be regularly monitored for changes in the aorta. Thus, the patient was submitted to aortic valve replacement with mechanical prosthetic valve and ascending aorta replacement surgery. The cardiac surgery was uneventful.

Contributors All authors made substantial contributions to the conception or design of the work, or the acquisition, analysis or interpretation of data; helped in drafting the work or revising it critically for important intellectual content; and approved the final version submitted to this journal. FC drafted the article. SSC, AF and JIM revised the article critically for important intellectual content. All authors approved the final version submitted to BMJ Clinical Cases and agreed to be accountable for the article and to ensure that all questions regarding the accuracy or integrity of the article are investigated and resolved.
Funding The authors have not declared a specific grant for this research from any funding agency in the public, commercial or not-for-profit sectors.

Competing interests None declared.

Patient consent Obtained.

Provenance and peer review Not commissioned; externally peer reviewed.

(C) BMJ Publishing Group Ltd (unless otherwise stated in the text of the article) 2018. All rights reserved. No commercial use is permitted unless otherwise expressly granted.

\section{REFERENCES}

1 Singh S, Hakim FA, Sharma A, et al. Hypoplasia, pseudocoarctation and coarctation of the aorta - a systematic review. Heart Lung Circ 2015;24:110-8.

2 Gay WA, Young WG. Pseudocoarctation of the aorta. A reappraisal. J Thorac Cardiovasc Surg 1969;58:739-45.

3 Kessler RM, Miller KB, Pett S, et al. Pseudocoarctation of the aorta presenting as a mediastinal mass with dysphagia. Ann Thorac Surg 1993;55:1003-5.

Copyright 2018 BMJ Publishing Group. All rights reserved. For permission to reuse any of this content visit http://group.bmi.com/group/rights-licensing/permissions.

BMJ Case Report Fellows may re-use this article for personal use and teaching without any further permission.

Become a Fellow of BMJ Case Reports today and you can:

- Submit as many cases as you like

- Enjoy fast sympathetic peer review and rapid publication of accepted articles

- Access all the published articles

- Re-use any of the published material for personal use and teaching without further permission

For information on Institutional Fellowships contact consortiasales@bmjgroup.com

Visit casereports.bmj.com for more articles like this and to become a Fellow 